Nepalese Vet. J. 35:9-22

\title{
Effect of Age and Frequency of Collection in Quality of Jersey Bulls Semen at National Livestock Breeding Center, Nepal
}

\author{
S. Sankhi ${ }^{1}$, K. R. Sapkota ${ }^{2}$ and B. Regmi*1 \\ ${ }^{1}$ Institute of Agriculture and Animal Science (IAAS), Rampur, Chitwan, Nepal \\ ${ }^{2}$ Veterinary Officer at National Livestock Breeding Center (NLBC), Pokhara, Kaski, Nepal \\ *Corresponding author: regmibharat2008@gmail.com
}

\begin{abstract}
The present study was undertaken to determine the effect of age and frequency of collection on quality parameters of Jersey bull semen at National Livestock Breeding Center (NLBC), Pokhara, Kaski district. Nine Jersey bulls were selected randomly from NLBC. To obtain the effect of age, six bulls of three different age interval (34, 5-7 and 8-9 years) were selected randomly. Remaining three bulls were used to determine the effect of frequency of collection on semen quality. Studies were conducted for three months (Nov/Dec to Dec/Jan 2017). Semen quality was analyzed using CASA system and SMILE software. ANOVA and paired t-tests were applied to find out level of significance. All the statistical analyses were done using SPSS 17.0. Sperm concentration $\left(0.551 \pm 0.004\right.$ to $\left.1.084 \pm 0.014 \times 10^{9}\right)$, post- thaw motility $(42.44 \pm 0.11$ to $51.72 \pm 0.03 \%)$, live sperm $(45.62 \pm 0.13$ to $51.23 \pm 0.15 \%)$, and abnormal sperm (11.57 \pm 0.12 to $19.59 \pm 0.24 \%)$ were significantly affected by the age of the bulls. Semen quality was found superior in the bulls belonging to 5-7 years of age intervals. On the other hand, volume $(3.98 \pm 0.09$ to $6.72 \pm 0.06 \mathrm{ml})$, initial motility (72.68 \pm 0.02 to $78.64 \pm 0.15 \%)$ and pre-filling motility (71.34 \pm 0.17 to $77.62 \pm 0.02 \%)$ did not differ significantly among different age intervals. Significantly, higher value for semen volume $(3.98 \pm 0.12$ to $6.02 \pm 0.14 \mathrm{ml})$, sperm concentration $(0.572 \pm 0.119$ to $1.095 \pm 0.015)$ and post- thaw motility $(40.34 \pm 0.21$ to $48.54 \pm 0.06 \%$ was obtained on second collection. However, initial motility (70.58 \pm 0.06 to $75.64 \pm 0.13 \%)$, pre-

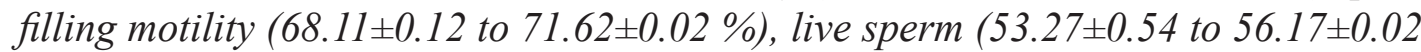
$\%)$ and abnormal sperm (12.31 \pm 0.12 to $14.3 \pm 0.47 \%)$ did not differ significantly between the frequencies of collection. Different quality parameters of semen like volume, concentration, initial motility, pre-filling motility, post thaw motility, live and normal spermatozoa percentage were higher in 5-7 years old bulls and in second collection of semen.
\end{abstract}

Keywords: Age; frequency; semen; quality; $N L B C$ 


\section{INTRODUCTION}

Livestock plays a vital role to the Nepalese economy and contributes about $11 \%$ to the total national gross domestic product (GDP) and about 26.8\% to national agricultural gross domestic products (AGDP) (MoAD, 2016). Dairying is the most important sub-sector contributing about $63 \%$ to the total Livestock Gross Domestic Products (LGDP) which is about $8 \%$ of total national GDP. It provides a daily source of income and has been well recognized as a means for poverty reduction across the developing world. In Nepal, the demand for milk and milk products is increasing. There is a need of high yielding breeds of dairy animals in order to meet the increased demand of milk. Genetic improvement is one of the prioritized activities of Government of Nepal to improve the productivity of the Nepalese cattle herd. Artificial Insemination (AI) is the cheapest way of improving the genetic potentiality in the indigenous cattle using the semen of exotic breed bull. AI may be defined as the collection of semen from a healthy proven bull by artificial means exteriorly, evaluating it for quality, extending it in a suitable extender and preserving the same in suitable temperature. This extended and processed semen is to be inseminated to an estrus cow during standing heat in mid cervix with the help of a sterilized mechanical device. AI was the first great biotechnology applied to improve reproduction and genetic advancement of farm animals. AI is not only important in genetic improvement but also beneficial for the control of venereal diseases, economical than the natural service, safe in eliminating injury during natural service and availing geographical restrictions (Bearden et al., 2004; Lemma \& Shemsu, 2015).

The process of cryopreservation and later on thawing for AI are known to adversely affect the survival of the sperm even under the best technique available today. Factors from selection technique of the bulls to semen processing and storage are believed to have different level of influence on the quality of semen produced and its fertility during application (Lemma \& Shemsu, 2015). The influencing factors for the success of AI program are quality and fertility of semen, skilled technician, an increase of AI coverage, and the farmer's awareness about the advantage of AI. The fertilizing capacity of semen depends on quantity (ejaculated volume) and quality (semen morphology, live concentration and motility) (Shamim et al., 2013). It was reported that total sperm per ejaculate increased with age of the bull up to 7.5 years and then decreased (Al-Hakim, 1986) . Vilakazi (2003) has suggested that the breed, age and season and their interactions are important source of variation in the sperm morphology and ultimately the production of best quality semen.

It is obligatory to perform the evaluation of semen, either fresh or frozen thawed to 
predict its fertility indices. Semen volume, concentration of spermatozoa, proportion of dead and abnormal spermatozoa, and motility of spermatozoa are recognized as important indices of semen quality and significantly correlated with freeze-ability and/or fertility of bovine semen (Fiaz et al., 2010). The evaluation of semen quality and quantity may help in selecting a good quality sire for the breeding purpose.

Sires contribute half of the genetic makeup of the offspring, so commonly called 'bull is half of the herd'. When artificial insemination (AI) is applied; each bull can serve thousands of female per year. The success of AI depends on the ability to screen for semen with high fertilization potential (Holt et al., 2007). Therefore, is extremely important to do the selection of breeding bull to improve their offspring (Kumar et al., 2015).

Reproductive efficiency of dairy cattle can be improved through utilization of highly fertile bull bearing excellent semen quality. The effective screening methods for ejaculates prior to processing are necessary for improving reproductive performance in bulls. The evaluation scheme of the jersey bulls, used for AI either does not exist or if any, poorly evaluated. All such bulls should be evaluated with the efficiency of conception of semen, which is used in AI program. As it has already been 40 years of application of AI in the country, it is necessary to find out the quality parameters of bull semen used for AI. Considering all above facts, the present research was undertaken to evaluate semen quality and quantity in relation to age and semen collection interval of different Jersey bulls in the National livestock Breeding Center (NLBC), Pokhara, Nepal.

\section{MATERIALS AND METHODS}

Research Site: National Livestock Breeding Center, Pokhara.

\section{Experimental Animals}

In this study 9 jersey bulls were used. According to the bull register, age of the bulls ranged from 3 to 9 years, body weight ranged from 390 to $1070 \mathrm{~kg}$, BCS (1 to 5 range) ranged from 4.0 to 4.5 and scrotal circumference ranged from 35 to $39 \mathrm{~cm}$.

\section{Semen Collection}

Usually semen collection was performed twice a week at NLBC. Two ejaculates were collected from each bull during each collection session and only the first ejaculate was used in this experiment. Collection was always performed in the morning between 7 and $9 \mathrm{AM}$. To determine the influence of collection interval, 3 consecutive collections from 6 selected bulls were done on Monday and Thursday. Semen was 
collected using artificial vagina (AV) method following standard procedure at homo sexual mount. The bulls were allowed at least two false mounts before collection of semen. Immediately after collection, the collecting tube was detached from the $\mathrm{AV}$, taken to the laboratory and placed at $37^{\circ} \mathrm{C}$ in water bath until evaluation and processing of semen.

\section{Evaluation of Semen}

The qualitative and quantitative examination of fresh and frozen semen was carried out through different methods as per protocol of NLBC mentioned in "Standard Operation Practice". First Draft uses the integration of smile software for data recording and CASA system for semen evaluation. Different quality parameters were used for the evaluation of the semen as mentioned in the Table-1.

\section{Preservation of Semen}

The egg yolk-tris-fructose-citric acid-glycerol was used as an extender. Briefly, a stock solution was prepared by dissolving tris $(297.6 \mathrm{mmol})$, fructose $(82.6 \mathrm{mmol})$, citric acid (105.3 mmol), penicillin G-sodium (1000 I.U/ml) and streptomycin sulphate $(1 \mathrm{mg} / \mathrm{ml})$ in glass distilled water. Fresh yolk was added with the buffer at a concentration of $20 \%(\mathrm{v} / \mathrm{v})$. The volume of extender was divided into two equal parts. Thereafter, glycerol was added to one part of the extender at two times of the desired concentration (12.8\%). The other part of the diluents was used to make the initial dilution of semen that contained two times of the desired concentration of spermatozoa. The initial dilution of semen was made at $+37^{\circ} \mathrm{C}$. Three equal parts of initially diluted semen and double concentration glycerol- containing extender were mixed together at four steps during a 2 to 3 hours cooling process, the dilution steps were at $+18,+12,+8$ and $+4^{\circ} \mathrm{C}$. Finally, the diluted semen contained $6.4 \%(\mathrm{v} / \mathrm{v})$ glycerol and 20x10 motile spermatozoa per $0.25 \mathrm{ml}$ French straw (one insemination 6 dose). Individual insemination doses were sucked in $0.25 \mathrm{ml}$ French straws and the open ends of the straws were sealed by using automatic filling and sealing machine. After loading, the straws were left for equilibration at $+4^{\circ} \mathrm{C}$ for 4 hours. The cooling and equilibration operation were done in a cold handling cabinet. After equilibration, the freezing operation was conducted in deep semen freezer to cool the semen from +4 to $-140^{\circ} \mathrm{C}$ during a period of $7 \mathrm{~min}$ and then the straws were directly plunged into liquid nitrogen $\left(-196^{\circ} \mathrm{C}\right)$. Only semen that showed equal to or more than $50 \%$ postthaw motility was preserved for AI. 


\section{Thawing of Semen}

To check the post-thaw motility and taking sample for formal-saline fixation, the frozen semen straws were thawed at $+37^{\circ} \mathrm{C}$ warm water for 30-40 sec at 24 hours post freezing.

\section{Experimental Approaches}

Experiment 1. In this experiment, the influence of age on semen quality with respect to volume color, density, initial motility, pre-freezing motility, post thaw motility, sperm concentration, semen doses produced, number of sperms per dose of semen were determined. A total of 9 jersey bulls of 3 age groups were selected in this experiment. Group-1 included bulls of 3- and 4-years group- 2 included bulls of 5, 6,7 years and group-3 included bulls of 8 and 9 years old $(n=3)$. Semen from these bulls was collected on Monday and Thursday.

Experiment 2. In this experiment, the influence of collection interval on semen quality with respect to volume color, density, initial motility, pre-freezing motility, post thaw motility, sperm concentration, semen doses produced, number of sperms per dose of semen were determined. Three Jersey bulls of 3 to 9 years old were selected for this study. All bulls were collected at 30 minutes 'interval for evaluation of semen for three consecutive times.

\section{Data analysis techniques}

All data were presented as mean \pm standard error of mean (SE). One-way analysis of variance (ANOVA) followed by least significant difference (LSD) was done to find out significant differences among the different age variables. Pair t-test was done to find out the significant differences between the two categories of collection interval of semen. All the statistical analyses were done using SPSS 17.0. The difference between groups was regarded as significant when the $\mathrm{P}$ value was less than 0.05 $(\mathrm{P}<0.05)$.

The following fixed effect model was used to express each observation of semen quality produced from breeding Jersey bulls.

Yijkno $=\mu+a i+b j+c k+g n+$ ho + eijkno

Where, $\mu$ is the overall mean

ai is the effect of $i^{\text {th }}$ year $(i=1,2,3,4,5)$

$b j$ is the effect of $\mathrm{j}^{\text {th }}$ bull $(\mathrm{j}=1,2,3,4,5,6,7,8,9,10,11)$ 
Nepalese Vet. J. 35:9-22

ck is the effect of $\mathrm{k}^{\text {th }}$ interval of semen collection $(\mathrm{k}=1,2,3)$

gn is the effect of $n^{\text {th }}$ density of fresh semen $(n=1,2,3)$

ho is the effect of $\mathrm{o}^{\text {th }}$ mass activity of fresh semen $(\mathrm{o}=1,2,3)$

eijklmno is the random element (error mean) assumed to be normally and independently distributed among the sampled population.

\section{RESULTS}

\section{Quality Parameters of bull semen production}

Quality parameter of bull semen includes physical quality (macroscopic quality) and microscopic quality. Physical quality parameters of bull semen included semen volume and density of semen. Similarly, microscopic quality parameters of bull semen included initial motility, sperm concentration, pre-filling motility, post thaw motility and abnormality of sperms. In this study, microscopic quality parameters of bull semen were initial motility, sperm concentration, pre-filling motility and post thaw motility.

Table 1: Quality parameters for the evaluation of bull semen

\begin{tabular}{|l|l|}
\hline Parameters & Descriptions \\
\hline Semen Volume & $\begin{array}{l}\text { Volume of semen in ml ejaculated by bull/ } \\
\text { ejaculation }\end{array}$ \\
Mass activity of sperms & $\begin{array}{l}\text { Density of semen (1-3 scale as fair, dense and highly } \\
\text { dense) }\end{array}$ \\
Initial motility of sperms & Mass movement of sperms in mass or group \\
Concentration of sperms & Initial motility \% of individual sperms of fresh \\
Pre-filling motility \% & semen \\
of sperms & Billion (109/ml) of sperms/ml of semen \\
Post thaw motility \% & $\begin{array}{l}\text { Motility \% of sperms after mixing with diluters and } \\
\text { before filling into the straws. } \\
\text { of sperms }\end{array}$ \\
Semen doses produced & $\begin{array}{l}\text { Motility \% of sperms after freezing of semen by post } \\
\text { thawing process of it. }\end{array}$ \\
& $\begin{array}{l}\text { Doses of semen straw prepared by per ejaculation of } \\
\text { semen. }\end{array}$ \\
\hline
\end{tabular}




\section{Influence of Age of Bulls on Semen Parameters}

The effect of age of bulls on semen quality is presented in Table 2. The highest volume of semen, motility, concentration, post thaw motility and live sperm were obtained from 5-7 years' age group $\left(6.72 \pm 0.06 \mathrm{ml}, 78.64 \pm 0.15 \%, 1.084 \pm 0.014 \times 10^{9}\right.$ / $\mathrm{ml}, 51.72 \pm 0.03 \%$ and $55.48 \pm 0.05$, respectively) and lowest from $8-9$ years' age group $\left(3.98 \pm 0.09 \mathrm{ml}, 72.68 \pm 0.02 \%, 0.551 \pm 0.004 \times 10^{9} / \mathrm{ml}, 42.44 \pm 0.11 \%\right.$ and $45.62 \pm 0.13 \%$, respectively) as shown in figure 1 . Lowest value of abnormal sperm was obtained from bull of same age interval. However, the differences in semen volume, semen density, fresh semen motility and pre-filling motility did not differ significantly among different age groups of bulls. Whereas sperm concentration, total spermatozoa per ejaculate, post-thaw motility, live sperm and abnormal sperm were significantly different $(\mathrm{P}>0.05)$ among different age groups of bulls.

Table 2: Effect of Age on Semen Quality of Bulls

\begin{tabular}{lcccc}
\hline & \multicolumn{3}{c}{ Age (years) } & $\begin{array}{c}\text { Level of } \\
\text { Quanificance }\end{array}$ \\
\cline { 2 - 5 } & $\mathbf{3 - 4}$ & $\mathbf{5 - 7}$ & $\mathbf{8 - 9}$ & $\mathrm{NS}$ \\
Volume (ml) in LS & $5.12 \pm 0.15$ & $6.72 \pm 0.06$ & $5.98 \pm 0.09$ & $\mathrm{NS}$ \\
$\begin{array}{l}\text { Mean } \pm \text { SE } \\
\text { Density (3 scale) }\end{array}$ & 2 & 3 & 1 & $*$ \\
$\begin{array}{l}\text { Concentration }\left(10^{9} /\right. \\
\text { ml) }\end{array}$ & $0.942 \pm 0.017$ & $1.084 \pm 0.014$ & $0.551 \pm 0.004$ & NS \\
$\begin{array}{l}\text { Initial Motility \% (LS } \\
\text { Mean } \pm \text { SE) }\end{array}$ & $72.54 \pm 0.11$ & $78.64 \pm 0.15$ & $72.68 \pm 0.02$ & NS \\
$\begin{array}{l}\text { Pre-filling Motility \% } \\
\text { (LS Mean } \pm \text { SE) }\end{array}$ & $71.64 \pm 0.13$ & $77.62 \pm 0.02$ & $71.34 \pm 0.17$ & $*$ \\
$\begin{array}{l}\text { Post thaw Motility \% } \\
\text { (LS Mean } \pm \text { SE) }\end{array}$ & $45.61 \pm 0.06$ & $51.72 \pm 0.03$ & $42.44 \pm 0.11$ & $*$ \\
$\begin{array}{l}\text { Live sperm \% (LS } \\
\text { Mean } \pm \text { SE) }\end{array}$ & $51.23 \pm 0.15$ & $55.48 \pm 0.05$ & $45.62 \pm 0.13$ & $*$ \\
$\begin{array}{l}\text { Abnormal sperm \% } \\
\text { (LS Mean } \pm \text { SE) }\end{array}$ & $14.67 \pm 0.06$ & $11.57 \pm 0.12$ & $19.59 \pm 0.24$ & $*$ \\
\hline
\end{tabular}

Density: $1=$ fairly dense, $2=$ dense, $3=$ highly dense. * Significant at $5 \%(\mathrm{P}<0.05)$; NS: Non-significant 


\section{Influence of collection interval on semen parameters}

Influence of collection intervals (first, second and third ejaculate) of semen on semen parameters are presented in Table 3 . The significantly $(\mathrm{P}>0.05)$ higher volume $(6.02 \pm 0.14 \mathrm{ml})$ of semen was found in the first collection then that of second and third collections (figure 2). The semen concentration $\left(1.095 \pm 0.015 \times 10^{9} / \mathrm{ml}\right)$, post thaw motility and $50.74 \pm 0.14 \%$ were obtained significantly $(\mathrm{P}>0.05)$ higher in the Second collection then that of First and third collections. Whereas density, initial motility, pre-filling motility, abnormal sperm and live sperm were obtained higher in the Second collection though did not differ significantly from other collection intervals.

Table 3: Effect of Semen Quality among Number of Collections

\begin{tabular}{|c|c|c|c|c|}
\hline \multirow{2}{*}{ Quality parameters } & \multicolumn{3}{|c|}{ Collections } & \multirow{2}{*}{$\begin{array}{c}\text { Level of } \\
\text { Significance }\end{array}$} \\
\hline & First & Second & Third & \\
\hline $\begin{array}{l}\text { Volume (ml) in LS } \\
\text { Mean } \pm \mathrm{SE}\end{array}$ & $6.02 \pm 0.14$ & $5.72 \pm 0.22$ & $2.98 \pm 0.12$ & $*$ \\
\hline Density (3 scale) & 2 & 3 & 1 & NS \\
\hline Concentration $\left(10^{9} / \mathrm{ml}\right)$ & $1.072 \pm 0.017$ & $1.095 \pm 0.015$ & $0.572 \pm 0.119$ & $*$ \\
\hline $\begin{array}{l}\text { Initial Motility \% (LS } \\
\text { Mean } \pm \text { SE) }\end{array}$ & $74.54 \pm 0.15$ & $75.64 \pm 0.13$ & $70.58 \pm 0.06$ & NS \\
\hline $\begin{array}{l}\text { Pre-filling Motility \% } \\
\text { (LS Mean } \pm \text { SE) }\end{array}$ & $70.64 \pm 0.13$ & $71.62 \pm 0.02$ & $68.11 \pm 0.12$ & NS \\
\hline $\begin{array}{l}\text { Post thaw Motility \% } \\
\text { (LS Mean } \pm \text { SE) }\end{array}$ & $48.54 \pm 0.06$ & $50.74 \pm 0.14$ & $40.34 \pm 0.21$ & $*$ \\
\hline $\begin{array}{l}\text { Live sperm } \%(\mathrm{LS} \\
\text { Mean } \pm \text { SE) }\end{array}$ & $53.27 \pm 0.54$ & $56.17 \pm 0.02$ & $54.34 \pm 0.32$ & NS \\
\hline $\begin{array}{l}\text { Abnormal sperm } \%(\mathrm{LS} \\
\text { Mean } \pm \text { SE) }\end{array}$ & $12.51 \pm 0.12$ & $12.71 \pm 0.25$ & $14.3 \pm 0.47$ & NS \\
\hline
\end{tabular}

Density: $1=$ fairly dense, $2=$ dense, $3=$ highly dense. * Significant at $5 \%(\mathrm{P}<0.05)$; NS: Non-Significant.

\section{DISCUSSION}

\section{Influence of age of bulls on semen parameters}

The overall volume $(\mathrm{ml} \pm \mathrm{SE})$ of semen produced by Jersey bulls was found $5.20 \pm 0.08$ $\mathrm{ml}$. This was similar finding as reported by (JLTA, 2004). The lowest volume of 
semen produced by Jersey bulls was observed in age of 3 and 4 year of bull. As they are becoming older, they give larger volume of semen which is also justified by the reports of (Serrano, 1984; Mathevon M, 1998b; Waltl et al., 2004). Similar to the present findings, increased semen volume with age and body weight has been documented elsewhere (Van Denmark \& Free, 1970). Serrano (1984) demonstrated that bulls from 2-5 years of age produce larger volumes of ejaculate compared to bulls less than 2 years of age and bulls older than 5 years of age. Increased volume of ejaculate, sperm concentration and semen motility has also been observed with the advance of age of the bulls (Mathevon et al., 1998a). It is also demonstrated that young bulls just coming into service produce as little as 1-2 million sperm per ejaculate, while fully matured bulls produce 10-15 million sperm per ejaculate. Moreover, Kumi-Diaka et al., (1981) indicate that sperm cell concentration is significantly higher in the younger matured bulls of 3-7 years compared to bulls of 7.5-10 years. Accordingly, it has been suggested for attention in semen quality due to variation in age of bulls. This increase in semen production and quality can be explained by the fact that size of the testis is regarded as the main factor determining the total number of sperm production correlates with age of the bulls (Brito et al., 2002b).

Density of mature Jersey bull of age interval 5-7 years is higher than any other age interval. This was similar finding as reported by Muhammed et al., (2000). The result of this study shows the concentration of Jersey bulls' semen of age 5-7 is $1.084 \pm 0.014$ which is higher than 3-4 age interval $(0.942 \pm 0.017)$ and $8-9$ age interval $(0.55 \pm 0.004)$. This may be due to proper handling of bull, proper management and well-established lab procedure. However, Ahmed et al., (2014) obtained less value for the concentration of Jersey bull, Sahiwal bull and local bulls. This may be due to seasonal variation.

Initial motility, pre-filling motility and post-thaw motility was higher in the bull of age interval 5-7 years. Fiaz et al., (2010) obtained the similar result $73.49 \pm 0.8,70.44 \pm 2.0$ and 50.67 \pm 0.24 respectively. Ahmed et al., (2014) obtained higher value for these parameters. This result may be due to proper lab protocol, well trained technician. Live sperm count is higher for the bulls of age 5-7 years age interval. There is great difference in the value of live sperm \% between the age intervals i.e. $51.23 \pm 0.15$, $55.48 \pm 0.05$ and $45.62 \pm 0.13$ respectively. Kondracki et al., (2003) obtained similar value for younger and lower value for old bulls.

Abnormal sperm \% was observed higher in the bull of age interval 8-9 years than that of adult and young. Ahmad et al., (1986) obtained higher value of abnormal sperm for the young bull and lower for the older bull. This variation may be due to breed differences. 


\section{Influence of collection interval on semen parameters}

Jersey bulls produced similar volume of semen during first and second ejaculate of semen collection but very low in third collection. Waltl et al., (2004) found slightly higher volume of first $(5.76 \pm 2.56)$ than second $(5.13 \pm 2.22)$ and third $(5.28 \pm 2.34)$ ejaculation. However, Everett \& Bean (1982) and Everett et al., (1978) found first ejaculates resulted significantly higher volume of semen then other ejaculation. This study has also shown the similar result that as the number of ejaculates increases, volume of semen reduces.

The density of semen usually correlated with sperm concentration so highly dense semen might have higher volume of semen. In Nepal, the average volume in highly dense and dense semen of Jersey having higher value than the same value of HF in Bangladesh as referred by (Sarder et al., 2000). Highest density was obtained at the second collection than the first and third collection. This may be due to the more stimulation of the male accessory reproductive organs, which produce more semen as the gland get more stimulated than the first ejaculation (Castillo et al., 1987).

The overall sperm concentration $\left(10^{9} / \mathrm{ml}\right)$ in semen of Jersey bulls was found to be $1.072 \pm 0.017$. When compared to Walt et al., (2004) report that ejaculate of breeding bulls contained sperm concentration $\left(10^{9} / \mathrm{ml}\right)$ slightly higher for first $(1.26 \pm 0.41)$, similar for second $(1.08 \pm 0.41)$ and lower for third collection $(0.95 \pm 0.41)$ on same day than present finding. Ahmad et al., (2003) reported lower overall concentration $\left(10^{9} / \mathrm{ml}\right)$ of sperms ejaculated from Sahiwal bull in Pakistan $(0.98 \pm 0.01)$ than present finding. This result may be due to more stimulation of bull for second ejaculation with the stimulation of the accessory reproductive organs. However, Vilakazi et al., (2000) obtained higher value for the first collection this may be due to proper handling, proper stimulation of bull prior to the semen collection.

Initial and prefilling motility was found almost similar in three consecutive collections. Initial motility for the first, second and third collection is $74.54 \pm 0.15,75.64 \pm 0.13$ and $70.58 \pm 0.06$ respectively. Similarly, pre-filling motility for first, second and third collection are $70.64 \pm 0.13,71.62 \pm 0.02$ and $68.11 \pm 0.12$ respectively, this result may be due to same breed same season and same age interval of bulls. JLTA (2004) reported in its publication the similar ranges of initial motility of sperms ejaculated in bull semen ranges from 70-95\%. Rekwot et al., (1987) also reported similar (to present finding) initial motility of sperm in exotic and crossbred breeding bulls $(74.65 \%$ during dry and $76.57 \%$ during rainy season).

Post thaw motility of sperms in frozen semen of Jersey bull was found $52 \%$ at Nepal (NLBC, 2009) and Adhikari (2008) reported slightly higher than present finding. The 
deterioration in post thaw motility \% of bull semen may be due to semen production laboratory practice, qualified technicians and pressure on more doses of semen production.

Post thaw semen motility was found to be $50.24 \%$, which is higher than the minimum motility percentage of DLS recommendation (40\%). In a study, Singh et al., (2000) found $49.5 \%$ motility of spermatozoa just after thawing while Rao \& Rao (1979) and Rao (1996) found 53.8\% motility. Blom (1950) mentioned that motility below 50\% was often associated with low conception rate or poor fertility. So, to compensate this, NLBC fills more no. of sperm cell per dose to achieve better conception rate. Our finding $50.24 \%$ is almost similar with Blom (1950) whereas it is higher than the motility of $43.1 \%$ as found by Malla (2005) and $45.29 \%$ as found by Shrestha (2007). This data also exceeds the data from the NLBC register in which the post thaw mean sperm motility per at 0 hour of freezing found to be only $48 \%$. This might be due to limited and most recent samples we used. These data indicate NLBC has been gradually improving the quality of frozen semen, which is also supported by the increase of the conception rate over the years.

Live sperm and abnormal sperm count almost remain similar in the first, second and third collection. This may be due to the same breed, age interval, season, managemental practices and proper laboratory procedure for semen evaluation. However, Kandracki et al., (2014) obtained more dead sperm in the first collection which may be due to the sperm residue that may be previously present in the male tract before semen collection.

\section{CONCLUSION}

The highest volume of semen, motility, concentration, post thaw motility, live sperm and lower abnormal sperm were obtained from 5-7 years' age group of Jersey bulls and lowest from 8-9 years' age group. The sperm concentration, post-thaw motility, live sperm and abnormal sperm were significantly different among different age groups of bulls. The significantly higher volume of semen in the first collection whereas semen concentration and post thaw motility were obtained significantly higher in the Second collection from other collection intervals.

Based on the above findings, following recommendations could be made:

- Older Jersey bulls of more than seven years of age do not produce a good quality semen.

- Semen form third collection in the collection day is not of the good quality to be processed for AI program. 


\section{REFERENCES}

Adhikari, R. (2008). Study on NLBC produced buffalo semen quality and its relationship with conception. Internship Report, Institute of Agriculture and Animal Science, Rampur, Chitwan, 5(1):8-12

Ahmad, K., Ahmad Maqbool, K., \& Ahmad, M. (1986). Cryopreservation of buffalo spermatozoa in Tris. Pakistan Veterinary Journal , 6(1): 1-3.

Al-Hakim, M. (1986). A comparative study on biochemical constituents of semen of Jersey and Jersey Sahiwal bulls. Indian Journal of Animal Science, 57: 1180-1186.

Bearden, H. J., Fuquay, J. W., \& Willard, S. T. (2004). Applied Animal Reproduction (6 ed.). Pearson Education.

Brito, L., Silva, A., Rodriguez, L., Vieira, F., Deragon, A., \& Kastelic, J. (2002b). Effect of environmental factors., age and genotype on sperm production and semen quality of B. indicus and B. taurus AI bull in Brazil. Theriogenology, 70: 181-190.

Castillo, E., Tizol, G., Alverez, J., Perez, M., \& Baez, R. (1987). Reduction of protein concentrates level in ratio for Holstein sires. Cuban Journal of Agricultural Science , 21: $247-251$.

Everett, R., \& Bean, B. (1982). Environmental influences on semen output. Journal of Dairy science, 65: 1303-1310.

Everett, R., Bean, B., \& Foote, R. (1978). Sources of variation of semen output. Journal of Dairy Science, 61: 90-95.

Fiaz, M., Usmani, R. H., Abdullah, M., \& Ahmad, T. (2010). Evaluation of semen quality of Holstein Friesian and Jersey bulls maintained under subtropical environment. Pakistan Veterinary Journal. 30(2): 75-78.

Holt, W. V., O’Brien, J., \& Abaigar, T. (2007). Applications and interpretation of computerassisted sperm analyses and sperm sorting methods in assisted breeding and comparative research. Reproduction, Fertility, and Development. 19(6): 709-18.

JLTA. (2004). Japan Livestock Technology Association. http://jlta.lin.gr.jp/english/

Kondracki, S., Wysokińska, A., Iwanina, M., Banaszewska, D., \& Sitarz, D. (2003). Effect of sperm concentration in an ejaculate on morphometric traits of spermatozoa in Duroc boars. Polish Journal of Veterinary Science, 14(1): 35-40.

Kumar, U. G., Patil, M. S., Lakde, C. K., Bonde, S. W., \& Ramteke, B. R. (2015). Assessment 
of semen quality in pure and crossbred Jersey bulls. Veterinary World, $8(10): 1266-$ 1272 .

Kumi-Diaka, J., Nagerathman, V., \& Rwuaan, J. (1981). Seasonal, age- related changes in semen quality and testicular morphology of bulls in tropics. Vterinary Research, 108: $13-15$.

Brito, L.F.C., Silva, A.D.E.F., Rodrigues, L.H., Vieira, F.V., Deragon, A.G., \& Kastelic, J.P., (2002b). Effect of environmental factors, age and genotype on sperm production and semen quality of B. indicus and B. taurus AI bulls in Brazil. Animal Reproduction Science, 70(3-4): 181-190.

Lemma, A., \& Shemsu, T. (2015). Effect of Age and Breed on Semen Quality and Breeding Soundness Evaluation of Pre-Service Young Bulls. Journal of Reproduction and Infertility, 6(2): 35-40.

Mathevon, M., Dckker, J.C.M, \& Buhr, M.M., (1998b). Environmental, management and genetic factors affecting semen production in French Montbeliard bulls. Livestock Science, 55: 65-77.

Mathevon, M., Buhr, R.M., \& Dckker, J.C.M, (1998a). Environmental, management, and genetic factors affecting semen production in Holstein bulls. Journal of Dairy Science, 81: 3321-333.

MoAD. (2015). Nepal Portfolio Performance Review. Retrieved November 20, 2017, from Ministry of Agricultural Development: http:/www.mof.gov.np/uploads/document/ file/Agriculture_NPPR-2015_20150913011507.pd

NLBC. (2009). Annual progress report 2009/10. National Livestock Breeding Centre. Pokhara, Nepal.: National Livestock Breeding Centre.

Rao, T., \& Rao, A. (1979). Fertility and its relationship with semen characteristics in crossbred bulls. Indian Veterinary Journal , 56: 33-36.

Sarder, M., Joarder, O., Ali, M., \& Imam, M. (2000). Influence of genetic groups, season and age on their semen characteristic of breeding bull. Bangladesh Journal of Genetics and Biotechnology, 1: 51-57.

Serrano, A. (1984). Criteria by which to evaluate fertility in bulls in Central America., (p. 65). University of 1llinios at Ubarna- Champaign, USA.

Shamim Akhter, M., Abul Kalam Azad, M., Zahidur Rahman, M., \& Ashraf, A. (2013). Study on the Quality of Semen of Different Genetic Groups of Bull from Khulna Region of 
Nepalese Vet. J. 35:9-22

Bangladesh. International Journal of Pharmaceutical and Medical Research, 1(1): 19-23.

Singh, S. P., Pandit, R. K., \& Bhadoriya, H. B. (2000). Sexual behaviour and seminal characteristics in Jersey Sahiwal and halfbred bulls. Indian Journal of Animal Science, 70(3): 279- 280.

Van Denmark, N. and Free, M. (1970). Temperature effect (Vol. 3). (J. A.D., G. W.R., \& V. D. N.L, Eds.) Academic Press.

Vilakazi, D. M. (2003). Factors affecting the quality of semen of A.I dairy bulls in South Africa.

Waltl, B., Schwarzenbacher, H., Perner, C. and Solkner, J. (2004). Environmental and age affects on the semen quality of Austrian Simmental bulls. Slovenia. 